\title{
Gerência Administrativa
}

\author{
Annibal J. Vieira
}

É com prazer que deixo aqui meu agredecimento ao I.C.A. pelos magnificos programas que me permitiram aperfeiçoar conhecimentos em "gerência administrativa". Assisti em 1956 a um Seminário Prático em Administração de Abastecimentos tendo oportunidade então de visitar e obstzrvar o funcionamento do "General Services Administration" (Washington, D.C. ); o "National Institute of Health" e o "National Naval Medical Center" (Blithesda, Maryland); o "Department of Purchase, Contracts and Supplies" (Chicago); a "International Harvester Co." (Chicago); a "Montgomery Ward and Co." (Chicago); a "Sears, Roebuck and Co." (Filadelfia); a "United States Rubber Company" (Nova York); "The First National City Bank of New York" (N.Y.); a bôlsa de Valores em Walt Street (N.Y.) e a "Ciba Pharmaceutical Products, Inc" (Nova Jersey) Em 1959 fiz um curso de Gerência Administrativa e de Orçamınto Governamental na Univer sidade de George Washington (Washington, D.C.) tomei parte no $82^{\circ}$ "Top Management Seminar" levado a efeito no "Department of thir Army" pelo "Ordnance Weapons Comand" (Rock Island, III); compareci à "Eatern Administrators Conference" promovida pela "American Society for Public Administration" na Universidade de Pittsburgh (Pa.). Visitei as instalações magníficas da "Alluminium Company of America $(A L C O A)$ em Pittsburgh e tomei parte num programa de demonstração do que se pode fazer hoje em dia com o emprêgo de máquinas eletronicas, levado a efeito plala "The National Cash Register Company" (Dayton, Ohio).

Cabe agradecer principalmente aos Srs. Co-Diretores do Escritório Técnico de Agricultura (Ponto IV - Ministério da Agricultura), que me possibilitaram realizar essas duas viagens de estudo e observação.

$\mathrm{N}_{\tilde{A} O}$ estamos aqui criando novidades. Muito ao contrário, estamos procurando relembrar velhos e corriqueiros artifícios empregados por intuição ou por estudo, aliados a um pouco da nossa experiência. Nosso objetivo é contribuir para que a motivação do trabalho se possa dar dentro de um ambiente de harmonia e afinidade de propósitos. 


\section{O TRABALHO}

O trabalho (emprêgo) poderá ser definido como necessidade do meio e conseqüência das aspirações humanas. Representa primordial objetivo para a maioria dos individuos, significa segurança, isto é, alimento, saúde, casa, etc. O primeiro estágio ocorre na luta pela vida com a caça, e pesca e a coleta de frutos, raízes, etc. quando exercido pelo homem como necessário à própria sobrevivência. Nesta fase, cada um era o chefe de si mesmo e cabia a cada um tomar decisões. Com a organização da família passou a existir certa subordinação a um "patrão", o pai, enquanto êle era o mais forte. Êsse foi o primeiro "gerente" dos negócios de interêsse comum da familia e deu origem ao postulado até hoje irrefutável de que chefiar é a arte de motivar pessoas a fazerem coisas.

Ainda na atualidade podemos considerar que o trabalhador agrícola é o chefe de si mesmo, enquanto guardar aquêles objetivos primários de autosobrevivência; tão pronto, entretanto, se afastar daquela fase em direção à industrialização, o trabalhador precisa, forçosamente, de converter-se em patrão ou empregado de alguém.

Com o correr dos anos e o progresso material do mundo o trabalho $\mathrm{vcm}$ se tornando mais especializado e provocando a substituição ou transformação de velhas em novas profissões. As inovações, resultantes de idéias espontâneas ou resultado de pesquisas para alcançar novos ou melhores resultados, têm forçado o homem a procurar saber cada vez mais. A evolução se fazia mais lentamente no passado e permitia a absorção natural das condições que se modificaram. Hoje, nosso mundo está aceleradamente se modificando e, por isso, precisamos de novos conhecimentos, de novas habilitações. A ciência e o progresso que ela traz está eliminando muitas das profissões atuais. Segundo o professor Lionel V. Murphy, do Colégio de Estudos Gerais da Universidade de Georges Washington, os trabalhos de escritório serão todos mecanizados dentro de dez anos. Em conseqüência, não teremos mais funcionários especializados em estatística, em contabilidade, etc. Haverá necessidade apenas de pessoal para recolher papéis e cartões a fim de usá-los nas máquinas. Modificações dessa natureza ocorrerão também noutros setores.

Devemos encarar com realismo as possíveis modificações que o progresso vem trazendo e nos devemos manter em dia com as novas exigências do trahalho, num aperfeiçoamento constante, para enfrentarmos novas responsabilidades, novas tarefas.

\section{O EMPREGADO}

Em 1959 assisti a um seminário sôbre gerência administrativa de alto nível em "Rock Island", Illinois. Um dos conferencistas submeteu-nos a curioso teste. Fêz distribuir pedaços de papel entre os 21 participantes e pediu que nêles fôsse escrita a data em que tivéssemos sido mais ofendidos. ein nossa dignidade profissional, por nossos superiores. Recebidos os papéis de volta, o conferencista declarou que, como previa, todos foram preenchidos, alguns citando dia e mês, além do ano e, um dêles remontando há mais de 
dez anos. Tal fato basta, por si só, para demonstrar que ninguém esquece as ofensas recebidas. Ninguém esquece o ridiculo a que é submetido, principa!mente se tiver ligação com o trabalho e partir de seu superior. Ninguém esquece injustiças e promessas não cumpridas. Tais feridas latejam sempre como um sinal de alarme clamando por uma oportunidade de vingança, uma oportunidade de ajuste de contas, de pagamento na mesma moeda. Com êsse exemplo queremos lembrar aos chefes que bem pesem suas palavras a fim de poder contar com lealdade e colaboração irrestrita do auxiliar e não com o trabalho material do escravo.

Muitas vêzes o chefe é procurado com sugestões que constituem, como $s a b$ ? de antemão, um amontoado de asneiras mas que, talvez, tenham sido pioduto de esfôrço hercúleo do empregado no sentido de ajudar aos seus chefes. Não será humano da parte dêsses receber mal a quem, só em sugerir, está mostrando interêsse pelo serviço. Nesta situação, o chefe hábil procurará Suavizar o impacto da recusa da sugestão, em têrmos acessiveis ao entendimento do empregado, mostrando o que desaconselha ou impede o recebimento da sugestão. Então, como fecho, deve agradacer a prova de interêsse demonstrado e encorajá-lo a procurá-lo quando tiver alguma idéia, pois êle, sem dúvida, que trabalha, que sente também os problemas, poderá cooperar para simplificar o serviço, aumentar a produtividade e melhorar a respectiva qualidade.

Por outro lado, não devemos nos dirigir ao auxiliar com ar autoritário, dizendo VOCE - TU, mas sim dizer "NÓS precisamos fazer isso e o Senlıor é quem está à altura de conseguir NOS ajudar a atingir êsse objetivo.

Em 1956 tive oportunidade de visitar o estabelecimento pioneiro em vendas por catálogo nos Estados Unidos da América: a "Montgomery Ward", Chicago, Illinois. Também tive ocasião de visitar estabelecimento afim, a "Sears, Roebuck \& Co.", em Filadélfia, Pennsylvania. Enquanto o primeiro utilizava métodos antiquados de supervisão, com uma fiscalização e medida do trabalho realizada por fiscais impassiveis e mudos, o segundo inprimia ao ambiente um ar de grande familia trabalhando para objetivo comum e empregando métodos modernos para motivação do trabalho, que sempre está evoluindo, e isso permite à companhia alcançar resultados verdadeiramente astronômicos. A organização eficiente de trabalho da Sears, como nos foi dado observar em Filadélfia, assombra e ao mesmo tempo entusiasma pela sua simplicidade. Tudo lá concorre para a maior eficiência. A direção da Sears tem sempre presente a necessidade de atualizar o sistema de trabalho, que surge, como acentuou o Sr. T. Friedricks, com a necessidade dá tarefa e a capacidade dos funcionários. Empenham-se por isso, em analisar os métodos em uso para reajustá-los constantemente ao momento presente. Uma das maiores preocupações da equipe técnica da Sears é ieduzir o custo de operações e aumentar a produção dos empregados. A loja de Filadélfia distribui cêrca de seis milhões de catálogos por ano e as doze organizações nos Estados Unidos da América distribuem quarenta milhões por ano. Os catálogos, impressos em Chicago, custam US\$ 2.50 por unidade, o que representa despesa anual de US\$ 100,000,000.00. Essa tremenda quantia promoveu a venda de três bilhões de dólares em 1955. A Sears atendia, em 1956 , a 15.000 pedidos diários, que elevam a 75.000 
nas épocas de Natal. Tudo isso é despachado no mesmo dia dentro do horário normal, sem a necessidade de trabalho extraordinário.

Ëste milagre de realização da Sears sòmente se realiza pela motivação inteligente do empregado que se torna um amigo da casa, sócio na luta e nos benefícios. Cada setor tem o seu quadro de honra para premiar não apenas os mais capazes mas também quantos impediram que um engano de um dos companheiros pudesse prejudicar o trabalho. O delator não é aceito mas o elemento que ajuda, que impede ocorra o êrro, é premiado com lotivories.

\section{CHEFIA}

Nosso próprio corpo encerra exemplo de magnífica "administração", "gerência" ou "chefia". A motivação de movimentos coordenados para alcançar um objetivo escolhido, sem quebrar os principios de respeito e de autnridade própria a cada órgão, que no todo se equilibra e compensa deficiências, numa complementação imediata e perfeitamente autônoma, dentro dos limites de zona de responsabilidade própria, tudo isso sob supervisão que verifica efeitos, analisa causas e determina os objetivos a alcançar, constitui magnifico exemplo de organização e chefia.

Quem chefia tem que ter objetivo a alcançar e a alcançar através de cutras pessoas.

Chefiar é arte complexa e, como vimos, começa em nós mesmos. Quem chefia deve ter sempre presente que está trabalhando com sêres humanos como êle próprio, não com máquinas. Deverá lembrar-se de que o ser humano vem ao trabalho com seus problemas, com suas esperanças e frustações; precisa ser compreendido, ajustado ao trabalho. Não deve jamais esquecer que, dentro de nós mesmos, trazemos alguma coisa como amor próprio, orgulho, lealdade potencial, desejo de reconhecimento e também, algum bom senso. Tais são os fatôres positivos, que poderão se transformar em negativos caso não mereçam a devida atenção. Isto nos leva a não acrəditar na ineficiência do trabalhador, mas a acreditar na incapacidade da çrefia.

A chefia, de fato, não se consegue em virtude de nascimento, diploma, categoria, título ou posição, mas sim em conseqüência de uma conquista por capacidade, conquista e reconhecimento que deverá saber conservar graças a procedimento correto e honesto para consigo mesmo e para com seus subordinados. Franqueza, paciência, compreensão e bom senso não fazem inal a ninguém.

Neste terreno de chefiar, é importante notar que a filosofia de fazer "porque quero", da imposição da vontade sem o devido entendimento, é atitude a empregar-se apenas como recurso extremo, pois o individuo nunca deve ser tratado como simples objeto, simples máquina. Quando se lidam com sêres pensantes, capazes de raciocinar, deve-se explorar também essa qualidade no trabalho a ser executado.

Um dos defeitos comuns aos chefes é falar muito e ouvir pouco. Outro é não se proporcionar tempo no serviço para pensar sôbre êsse. Êle deve 
se conter para não continuar realizando aquilo que já fêz como subordinado pois agora é pago para consegui-lo através dos auxiliares. O chefe sempre lembrará que as pessoas são complicadas e respondem a diferentes estimulos. Por outro lado, é preciso não assumir importância inexistente. Chefiar é função paralela, cuja dignidade e mérito são iguais a qualquer outra dentro da organização e quanto mais importante mais dependente ela se torna da ccoperação de maior número de pessoas. Chefia é também uma especialização no trabalho.

As queixas dos empregados muitas vêzes não resultam do fato de quererem ser chefes mas sim por não estarem êsses a altura da função. Não é usando a "autoridade da posição" mas através da "autoridade do conhecimento", que o sucesso é alcançado. Para isso, o chefe deve ser responsável pelo próprio aperfeiçoamento e possibilitar que isso ocorra com seus subordinados.

Os empregados bons e eficientes - que não erram, nem criam problemas - são muitas vêzes esquecidos pelos chefes. O barulho, a azáfama, quase sempre procuram encobrir a incompetência. Para evitar essa omissão, deve o chefe procurar um contato mais direto com seus auxiliares, a fim de avaliar a possibilidade de dar-lhes melhores oportunidades e mais autoridade. $\mathrm{Na}$ análise dos individuos poderão ser tentadas, entre outras, as seguintes investigações, quanto ao auxiliar:

- Estaria êle disposto a pagar o preço do sucesso?

- Estaria fazendo mais do que sua obrigação?

- Estaria disposto a assumir mais responsabilidade e possiveis riscos?

- Tem aprendido com seus erros no trabalho?

-- Distribui seu tempo, de forma a tirar o máximo proveito no serviço?

-- Tem método no que faz?

- Tem personalidade?

- Tem paciência para ouvir?

- Consegue inspirar confiança aos companheiros?

- Sabe comunicar idéias?

- Teria ocupado posição de maior destaque anteriormente?

- Em que outro lugar poderia ser aproveitado?

O empregado que satisfazer considerações como essas deve ser preparado para cargos de mais destaque e de chefia: jamais desapontará. O còrefe deve procurar auxiliar seus funcionários como anteriormente já foi ajudado. Em pergunta feita a trezentos chefes numa companhia norte-americana. "Como você alcançou esta situação de responsabilidade e autoridade?", a resposta foi simplesmente: "Fui ajudado".

Nos Estados Unidos, para a troca de idéias sôbre problemas de chefia, são promovidas reunióes periòdicamente. Assisti a um dêsses conclaves, real:zado pela "Eastern Administrators Conference", em Pittsburgh. Verifiquei, entretanto, que consistem mais na apresentação do que na solução de prob!emas. Todos querem falar e falam mas não informam o que realmente pensam, pois são competidores no mesmo campo de trabalho e idéias, representam dinheiro e posição. Descobrem, isso sim (foi ao meu ver o único mérito alcançado) que todos estão defrontando com dificuldades semelhantes. 
Eis algumas, entre outras: como manter o empregado; como e até que ponto é fossível motivar o trabalho; como descentralizar a supervisão e continuar sendo "importante", porém, ao mesmo tempo, manter contrôle e autoridade; como evitar que os Sindicatos dificultem a mecanização do trabalho; como balancear o uso da máquina e o desemprêgo; como incentivar novas profissões decorrentes do progresso e, principalmente, em que ocupar o homem quando o trabalho pràticamente estiver sendo feito por máquinas? Essa a maior prencupação dos sociólogos.

\section{A MOTIVAÇÃo}

O mêdo, a insegurança como fator para motivar o serviço já é coisà do passado e deve ser substituído pela utilização da psicologia, a fim de alcarçar resultados duradouros e maiores. Requer, sem dúvida, paciência e ferseverança para que se consiga fazer com que o auxiliar sinta com os sentidos do chefe, com que veja com os mesmos olhos, com que tenha os mesmos objetivos e com que tenha confiança e fé na direção e aceite, portanto, sem restrições, as instruções recebidas. É fundamental, na motivação do individuo, que êle se sinta importante no que esteja fazendo e, para isso, é indispensável ao chefe reconhecer o esfôrço feito pelo empregado. mesmo quando erre. Não deve esquecer também de elogiar o trabalho realizado, pois a vaidade é grande predicado humano e uma das alavancas para incentivar e aprimorar a qualidade do trabalho executado.

A respeito de êrro ou engano que possa ocorrer durante o exercício das respectivas atividades convém levar em conta sempre que sòmente está sujeito a êrro quem trabalha e que todo empregado representa capital investido mensalmente pelo órgão empregador através dos salário e instrução. Crnvém analisar a causa do êrro, antes de qualquer providência punitiva. Teria sido proposital? É costumeiro? Decorrente, talvez, da estafa, do desinterêsse pelo tipo de trabalho? Por falta de capacidade ou habilidade para a tarefa? Em conseqüência de desarmonia e mau entrosamento entre os companheiros, quem sabe?

A N.C.R., Dayton, Ohio, manda a exame médico, a entrevista com assistente social e a testes de capacidade, habilidade e tendências, os operár'os de produção considerada insatisfatória. Com tais providências, as falhas sũo corrigidas e raramente o empregado é dispensado, naquela magnifica organização.

Por sua vez, a "Sears, Roebuck \& Co.", Filadélfia, insiste junto aos empregados que a Companhia não encoraja nem premia aos denunciadores de erros, mas sim a quantos impedem sua ocorrência.

Certa ocasião deparei com um servidor que não prestava a devida atenção ao serviço executado. Impontual, estava para ser dispensado por ineficiente e criador de casos com os companheiros de trabalho. Procurei analisar a causa de tudo isso e apurei:

19) Responsável por familia numerosa, necessitava ocupar-se fora do serviço para equilibrar o orçamento. Por êsse motivo rebelava-se contra o 
horário fixo e, quando não conseguia escapulir mais cedo ou chegar mais tarde, faltava ao trabalho.

2:) Tinha regular instrução, gostava de cálculos, de investigar e analisar problemas. Indivíduo esperto, dinâmico, estava encarregado de serviço rotineiro e monótono, impróprio ao seu temperamento.

Consegui me fosse dada oportunidade de procurar recuperar êsse elemento em um mês. Chamei-o e, particularmente, confessei-lhe que me deparava com sério problema para o qual desejava o auxilio dêle. Em compensação, passaria êle a ser o responsável pelo serviço onde trabalharia sòzinho e que poderia ser feito como e no horário que melhor lhe conviesse. Apenas fazia questão de que o trabalho ficasse pronto diàriamente e me fôsse apresentada a análise do que era meu objetivo. Tratava-se de um serviço de contrôle, investigação e análise mas estava eu certo de que the seria possivel executar. Tal como esperava êsse funcionário tornou-se dos mais eficientes elementos na organização. Seu trabalho era impecável e executado no horário que preferia; o importante para mim, o trabalho executado a tempo e a hora, isso era religiosamente alcançado.

Nesse caso consegui despertar o interêsse do indivíduo, além de espicaçar-lhe a vaidade e atender ao seu dinamismo, que lhe permitia ocupar o tempo disponivel para melhorar seu orçamento. $\mathrm{E}$ isso, precisamente, não tinha meios de fazer antes.

Para motivar alguém é necessário levar em conta as características básicas do indivíduo, que são:

- físico

- sentidos

- habilidades

- inteligência

- educação

- personalidade

Isto ajuda a determinar as aptidões do homem para o serviço sendo necessário aprender e treinar para executar. Muito embora tenha conhecimento, habilidade e personalidade, se o homem não conseguir que as tarefas sejam executadas, não será bom chefe.

Nem sempre somos felizes em conseguir motivar os indivíduos para fazerem como desejamos: todos nós temos fracassos. À propósito, contarei o seguinte episódio: Fui encarregado de modernizar os métodos de trabalho em certa organização. Vaidoso com os resultados de tese, que pouco antes havia apresentado sôbre racionalização de serviços de arquivo e protocolo, procurei usar a oportunidade para introduzir livros e fichas conseqüentes ao funcionamento do meu sistema. O encarregado do serviço era um funcionário moreninho, de compleição franzina, olhos febris e bigode ralo. Senteime ao seu lado e durante uma hora expliquei-lhe detalhadamente tudo como devaria ser feito $e$, ao mesmo, mostrava-lhe as fichas que deveria utilizar e os livros a preencher. Terminada a exposição, perguntei-lhe se havia sido cìro, se êle havia aprendido a manejar tudo. Cândidamente respondeu-me que não e pediu-me para repetir. Após outra explicação, ainda mais rica em detalhes, disse-me: "Não pense o Senhor que é má vontade minha mas 
o processo que deseja instituir é muito difícil e complicado; sinceramente, por maior atenção minha vai levar tempo para que eu possa fazer isso. Por que não me deixa continuar da maneira como venho fazendo? Tudo corre tão bem." Embora soubesse como o serviço era feito pedi-lhe que me explicasse o funcionamento dêle. "Olhe, é muito simples. Só uso um livro. À medida que os documentos vão chegando nêle coloco o número e deixo o o resto da linha para anotar o destino do documento." Tratava-se de um protocolo complementar, secundário, de um registro central. Perguntei-lhe então quando o espaço da linha em continuação ao número lançado se esgotava, como procedia. A resposta foi angélica. "Ora, lanço novamente o número do processo e fico outra vez com local para anotar a respectiva movimentação. Isso faço quantas vêzes fôr preciso". Quis dar-lhe um xeque-mate: solicitei ao funcionário que me informasse com quem estava determinado papel. Contestou-me da forma mais inesperada possível. Pcrguntou-me se não era um processo com a capa um pouco rasgada no canto superior direito e escrito com letra verde na parte inferior. Esse documento achava-se com o Dr. Fulano, concluiu triunfante. Fui verificar e estava mesmo. Resolvi então deixar que aquêle homem continuasse com o processo dêle pois jamais vi pessoa com tão prodigiosa memória. Não falhava e quase nunca necessitava daquele horroroso livro, entendido sòm॰nte por êle. Disse-lhe, entretanto, que estava proibido de entrar em férias, de adoecer ou faltar ao serviço enquanto eu estivesse lá. Falhei, reconheço, pois deveria ter modernizado o referido protocolo mas, tinha tanta ccisa a fazer na ocasião e muito mais importante, que resolvi deixar as coisas como estavam, Acabei sem outra oportunidade de tornar aquêle protocolo eficiente para qualquer um e não apenas para o referido moço.

A motivação das pessoas é arte a que se dá grande atenção. É empregada em todos os setores e não apenas na técnica de produção ou na execução de tarefas pelos empregados. Ninguém compra aquilo que imagina pois o fabricante e o vendedor pensam por êle, com antecedência, e lhe motivam a preferência, a preferência quanto ao produto que possuem, que podem manufaturar e que é mais conveniente a êles e não a nós. Prova disso encontramos na publicidade hoje em dia.

Procurou-me, certa ocasião, uma pessoa a fim de me expor um problema. Grande número de fregueses, que lhe tinham comprado artigos para pagamento em prestações, estava em débito havia muito tempo. Sugeri a meu amigo que expedisse um telegrama lacônico avisando que se as prestações vencidas não fossem satisfeitas até o fim do mês, o assunto seria entregue ao advogado da firma para as providências legais. O homem não acreditou no conselho mas o seguiu e ficou admirado ao recuperar $80 \%$ de tais débitos insolváveis, que embora de pequena monta cada um, reunidos, somavam a impo:tância significativa.

\section{CAUSAS E EFEITOS}

Em programa de televisão foi abordada a questão do menor abandonado. A solução encontrada para o problema foi a de prover com viaturas ao órgão público para capturar os menores que enfeiavam o panorama turístico de Copacabana; ao mesmo tempo, criadas maior número de vagas para 
internação dêles, tudo a expensas do Govêrno mas, evidentemente, pagas com dinheiro do povo. Ninguém procurou, naquele programa, nem de leve, pesqujsar a "causa" da existência do menor abandonado. Cuidou-se de remover os "efeitos" mas, evitar a ocorrência dêsses "efeitos", procurando analisar a causa, a razão da existência do menor abandonado para, não digo impedir totalmente a possibilidade mas, pelo menos, evitar que isso acontecesse no crescendo que se verifica - isso não se cogitou por falta de capacidade ou por comodismo dos "chefes", que preferem medidas aleatórias ou então a desculpa da falta de meios, do que "trabalhar" realmente o problema estabelecendo um programa realístico, objetivo, para ser executado. A fabricação do menor abandonado continuará cada vez maior e, cada vez maiores, serão os recursos necessários para dar sumiço ao infeliz ser humano jogado às vicissitudes da vida por uma sociedade desajustada em decorrência de "chefes", de "administradores", que talvez procurassem remover os inconvenientes do vasamento de um cano d'água ou colocando panos para absorver a água que corre ou mudando-se de lugar. Vedar o vasamento, remover a "causa" é, realmente, o que comporta fazer no caso. De fato, em tudo na vida, devemos nos lembrar que ninguém dá o que não tem.

Quem dirige deve preocupar-se com fatos, não com opiniões. Essas, quando pessoais, dificilmente levam a conclusões e a resultados. Fato ccncreto não se esvai quando se pergunta: Por que? Assim, é preciso trabalhar com causas, não com efeitos. Convém sempre procurar a causa do problema. Finalmente, deve-se trabalhar com as razões, não com desculpas, pesquisando-se aquelas por menores que sejam. Detendo-nos um pouco mais neste tópico, poderemos dizer que reunir duas placas de madeira com a utilização de pregos e martelo será mais ràpidamente conseguido do que se cfetuarmos a operação com verruma, parafusos e chave de fenda. Seguindo os princípios expostos, procurariamos conhecer as razões que nos le:ariam a escolher um dos processos enumerados. Neste particular, as condições existentes na ocasião influem decididamente no trabalho e justificam modificações nos métodos em uso, para satisfazer a novas exigências.

Concluímos então: antes que se dê início a um programa de trabalho é preciso analisar a tarefa e as diversas maneiras de executá-las; só então será escolhida a forma de resolvê-la, em face aos recursos disponiveis.

\section{ORÇAMENTO}

Nenhum planejamento é bem conduzido quando não se levam em consideração as disponibilidades orçamentárias. Poderemos definir o processo orçamentário como a formulação e adoção de um plano de atividades no qual se relacionam custo e recursos para realização de certo trabalho (objetivo) em periodo de tempo pré-determinado. O orçamento é, assim, e tão somente, plano financeiro de atividades para determinado período ou propósito.

orçamento público procura devolver e inverter em benefício do povo tudn quanto tenha sido arrecadado, propiciando o aumento da riqueza do Faís. $\mathrm{O}$ orçamento privado tem por objetivo aumentar os bens individuais ou de grupos pessoais. Enquanto os objetivos daqueles são destinados à receita indireta, os dêste são imediatistas. 
O povo, em sua maioria, não tem dado muita atenção ao orçamento público, esquecendo-se que, produto do seu trabalho, do seu suor, representa mola vital do progresso. O orçamento público é (ou deveria ser) o contrapêso da balança que influirá no equilibrio econômico do povo, incentivando ou contendo atividades, para que o país não cresça desordenadamente, com evidentes transtornos para o bem-estar social.

A elaboração orçamentária governamental é difícil num país que atravessa crise inflacionária, devido à dificuldade de previsão da despesa. Para corrigir essa situação seria necessário maior maleabilidade na utilização dos recursos, muito embora haja os perigos das dotações globais. A rigidez na aplicação de verbas, amplamente especificada em detalhe, permite análise nclhor e particularizada da despesa; traz, entretanto, por outro lado, inconvenientes resultantes das dificuldades, que aparecem no caso de planejamento reculistico de programa, estabelecido com muitos meses de antecedência. Para fugir a essa rigidez, parece-me, criou o Govêrno autarquias e órgãos paraestatais, não removendo a causa mas procurando solucionar os efeitos. - Outros "efeitos" continuam existindo clamando por providências e outros surgirão. Incrivel como os responsáveis fogem ao uso tão simples do "por que?". - Com isso aumentou consideràvelmente o custo dos investimentos e criou estado dentro de estado, poder dentro de poder e dificultou, sobremodo, o equilibrio de esforços necessários ao crescimento harmônico da riqueza pública.

Precisamos ter coragem para evoluir, para atualizarmos nossos conceitos, para vivermos a época presente e abandonarmos tudo que não se coadune corr a mentalidade moderna, que represente uma experiência do passado, escoimada porém, de seus erros. São necessários propósito, coragem e confisnça para levar avante uma idéia.

\section{PLANEJAMENTO}

O bom senso nos indica que tarefa fácil é aquela simples de ser executada e não fatiga, nem física nem mentalmente.

Com essas diretrizes em vista, poderemos estabelecer alguns ensaios básicos, gerais, para simplificação do trabalho. cuja meta principal é reduzir os movimentos e, conseqüentemente, a estafa. O resultado será, evidentemente. economia de tempo.

A programação do trabalho, destinado a alcançar êsses resultados, deverá prever arrumação em seqüência, que permita alcance permanente de objetos, evitando-se, tanto quanto possivel, a necessidade de andar para atingi-los ou a necessidade de movimentos descontínuos. O corpo todo deverá ser empregado com o mesmo propósito para um equilibrio de movimentos ritmados.

A posição do individuo na mesa de trabalho é assaz importante. Convém ter em vista sempre que a zona de alcance para a tarefa deverá ficar circunscrita aos semi-circulos alcançado pelos braços, sem necessidade de inclinação 
do corpo. Por outro lado, a distribuição do material de trabalho ficará em boa ordem e tão próxima quanto possivel do interessados.

O método usado para execução de uma tarefa é muito importante. Inf!ui, mais que qualquer outro fator, no tempo gasto para sua execução; - planejamento antecipado é medida indispensável à realização de trabalho racional, sem práticas empíricas, empregadas à medida que as dificuldades strgem. Assim, hoje em dia, podemos aconselhar, antes de qualquer progra$\mathrm{ma}$, que se indague:

\section{- como \\ - quando \\ - por que \\ - e de que forma}

Isso é necessário para estudar a tarefa, analisar as diversas maneiras de executá-la e escolher a mais conveniente. Devemos nos perguntar então: Qual o objetivo? Existe algum problema? Quanto tempo levaremos para resolvê-lo? Com que elementos contamos para o trabalho? Quais os resultados a que desejamos alcançar primeiro? E depois? Quem nos poderá ajudar? É o fator tempo muito importante na conclusão das tarefas? Será econômico usar a máquina ou o homem? Em outras palavras, precisamos reunir todos os elementos pertinentes ao serviço antes que seja escolhido o caminho a seguir.

O importante no planejamento de um trabalho náo é escolher o melhor caminho, mas aquêle incluido nas possibilidades materiais e que também nos leve cos mesmos resultados. Dentro dêsse princípio, por mais completo, por mclhor que seja qualquer sistema, devemos ter em mente que ronhum trabalho poderá ser executado de uma só maneira. Pensar-se assim é ficar amarrado au passado sem vislumbre de aperfeiçoamento e progresso.

Quem planeja, quem dirige deve usar e abusar das palavras por que? Essa interrogação permitirá ajuizar se há ou não necessidade da providência. da vantagem da modificação. Não deve porém aceitar resposta que envolva opiniẽ̃o pessoal mas, ao contrário, fatos concretos.

Estamos numa época de luta feroz contra o tempo, na qual todos procuram dilatar os minutos para conclusão de metas em período cada vez mrnor. Isso já se tornou mesmo psicose e não nos podemos livrar dela. A propósito, contarei o que se passou comigo nos Estados Unidos da América. Estava eu em companhia de um oriental em visita a Nova York. Tinhamos pouco tempo e muito o que ver. Na estação do "subway" que fica próxima ao "Times Square" corria eu para apanhar uma das composições quando meu amigo segurou-me pelo braço. "Espere, por que você faz questão de apanhar aquêle trem? É o último?" "Respondi-lhe: "Claro que não. Mas o outro só passa daqui a 10 minutos". "E o que vamos fazer com êsse punhado de 10 minutos, que ganharmos?" Colocá-los no bôlso?" Mİ 11 companheiro tinha razão. Comprei um saco de pipocas e pacientemente esperei pela próxima condução. 
îste episódio serve pará ilustrar como somos contaminados pelo meio. Assim é que, na era do jato, ninguém mais tem calma e, àquele com a tarefa de organizar ou de planejar, cabe não se deixar envolver pela pressa, que faz, amiúde, omitir detalhes importantes.

Não estamos com isso querendo advogar os métodos e processos antigos mas, tão sòmente, aconselhando calma e um pouco de meditação antes das decisões.

A simplificação do papelório, a objetividade da escrita e sua clareza. isenta de expressões supérfluas, é uma das mais procuradas metas na terra do Tio Sam. Ao analisar isoladamente uma carta, por exemplo, não chegamos a imaginar o desperdício de tempo e dinheiro que vai tanto por parte de quem escreve, de quem a datilografa, como de quem a lê. Isso não levando em conta o material consumido e as despesas de circulação com a referida carta até sua destruição. Em grande escala, o tempo desperdiçado e as despesas montam a cifras muito significativas e, no referido país. constitui prcocupação a simplificação não só dos papéis, mais ainda de tudo quanto resulta em economia de tempo e de material.

A linguagem escrita, pouco e pouco, é escoimada dos floreios literários para entrar no terreno objetivo, claro, sem possibilidades de interpretações diferentes daquela que se quis alcançar. Evita-se, com isso, principalmente, que se pulem parágrafos por vêzes julgados enfadonhos ou desnecessários e que, talvez, escondam alguma coisa importante. Tempo houve em que o conhecimento do idioma era mostrado pela extensão das sentenças: longos períodos onde a maestria estava em não se repetir palavras. Ninguém poderá - negar a beleza de tudo isso, mas a época moderna não comporta tais dissertaçc̃es, que ficam bem nos recintos literários ou no fraseado dos pareceres juridicos. A linguagem hoje é telegráfica, no sentido de economia de palavras e, conseqüentemente, de custo,

Planejar é a função básica do administrador, chefe ou gerente. O sucesso ou fracasso em qualquer negócio depende muito do cuidado com que fôr construido o arcabouço da organização, estabelecidas as rotinas de serviço e de autoridade, mas também os requisitos necessários a cada pessoa.

Um dos grandes entraves ao trabalho é a falta de autoridade de quem dirige decorrente da centralização total dessa. Isso cerceia o espírito de iniciativa e retarda decisões. Cabe, ao se planejar algum órgão, levar em conta que a descentralização da chefia imprime maior impulso ao trabalho e até mesmo maior fiscalização no "ponto de causa", o que não ocorre com a autoridade centralizada, que "se apercebe dos efeitos", algumas vêzes tardismente.

Descentralizar, no caso, é como que uma especialização da autoridade da chefia. O Chefe, qualquer que seja, não pode ser considerado um boneco sem alma e, por isso, a respectiva escolha é tarefa árdua. Orientarse-ć, inicialmente, pelas" qualidades espontâneas de lider natural, mas considerará também os conhecimentos do serviço que vai dirigir para que tenha confiança em si mesmo e consiga inspirá-la nos que dirigir. 


\section{A ESPECIALIZAÇÃO E A MÁQUINA}

Muito embora pareça o contrário, é nos Estados Unidos da América que tem ocorrido maior resistência ao emprêgo da máquina. Esta reação natural tem raizes profundas na formação do povo. Êsse foi constituído por grupos rebelados contra a tutela do corpo e do espirito, que correram para tal país no anseio de pensarem e agirem livremente, sem a sujeição vexatória do Estado, que agrilhoava as liberdades de crença, que não reconhecia o mérito nem a igualdade de direito do homem humilde e ferrenhamente impedia a evolução das massas em benefício de grupos de castas sociais. Com êsses princípios de formação e na impossibilidade de proporcionar-se a todos uma instrução de alto nível, foi decidido que todos teriar. uma base mínima, ficando o alto nível para o futuro, quando todos estivessen de crrta forma em pé de igualdade, com as mesmas oportunidades e poss:bilidadies. Era necessário porém, homens mais instruidos que a massa dos cidadãos norte-americanos, em quantidade impossivel de obter a curto prazo i) país. Foi usado então o expediente mais simples e objetivo: importar valores. O recebimento de técnicos, cientistas, sábios mesmo, foi bem acolhido e assimilado pelo país onde não existia o elemento nativo concorrerie.

A especialização que imperava de modo absoluto e agora se atenua foi consequeência natural da rudimentar instrução que desde cedo impelia os jovens a se apegarem aquilo, para que tivessem mais pendor. As idéias religiosas dos colonizadores, que seguiam à risca o lema de "trabalha que te ajudarei", criou a mentalidade americana, pouco comprcendida aliás, segundo a qual é pecado ajudar ao vagabundo, que não admite fique alguém sem exercer atividades, que aos próprios filhos conduz ao trabalho como virtude e nem sempre como necessidade e que, sòmente ajuda ao semelhante nos infortúnios mas quando o faz impõe a condição de trabalho.

A máquina aparecia como o elemento capaz de proporcionar os mesmos recursos e as mesmas oportunidades a cada qual, num nivelamento de capacidade que não fôra possibilitado a todos. Surgiu, entretanto, certo conflito intimo, muito sério, na mentalidade nacional. Seria justo que a máquina vicsse substituir o trabalho humano? E o que iria acontecer com êle? Não scria isso infringir os próprios princípios básicos de liberdade do individuo?

A justificativa para que essas conjeturas fôssem esquecidas veio com a Primeira e com a Segunda Grande Guerra. Durante aquela, por exemplo, foi possivel a introdução da máquina de escrever nas repartições públicas e noutros lugares, pois o tremendo impulso nas atividades veio exigir meio 1apido de escrita até então feita por caligrafos. As máquinas de escritório, inclusive as contábeis e tôdas as outras, foram surgindo como condição imp:escindivel para atender à massa de serviço. O respeito à dignidade do trabalhador, entretanto, não foi esquecido: ficaram nos seus lugares até que naturalmente desapareceram.

Mas o povo despertou um dia alarmado. Lembrou-se de que a máquina iicidia mais duramente na atividade especializada. naquela que nem todos podiam executar e que passavam a ser possiveis a uma grande maioria. O pavor do desemprêgo, o mêdo de ter que aprender outra profissão fêz com 
que o homem se arregimentasse e fincasse o pé no terreno, em busca de segurança para si. A mecanização passou a ser surdamente combatida e motivou, de parte das emprêsas, a política de criar outras condições de trabalho para seus empregados que viessem a ser dispensados com a utilização da máquina.

Essa possibilita a uma maioria executar tarefas especializadas de uma minoria. A máquina multiplica a capacidade do homem e dignifica o seu trabulho. Com tudo isso, a reação é grande por parte dos Sindicatos, tão grande que um estabelecimento militar teve que dar satisfações a um dêsses, a fim de esclarecer que a instalação de um computador eletrônico não motivaria a dispensa de empregados e sua utilização era destinada, exclusivamente, a experimentos e ensino.

Com tôdas as reações, entretanto, a máquina cada vez mais se impõe, comn necessidade, para atender a novas condições de vida e progresso. A "Ciba Pharmaceutical Products", em New Jersey, mantem um dos melhores e mais completo serviço de escritório e fabril mecanizados, que vimos nos Estados Unidos da América. Com surprêsa fomos informados e verificamos niesmo que nenhum empregado forra despedido. A firma teve mesmo que admitir mais funcionários especializados e hoje seus técnicos vigiam as máquinas em trabalho e ganham muito mais devido ao barateamento da produção. 